\title{
NW Pacific slab rheology, the seismicity cutoff, and the olivine to spinel phase change
}

\author{
John C. Castle and Kenneth C. Creager \\ Geophysics Program, University of Washington, Seattle, U.S.A. \\ (Received April 27, 1998; Revised August 24, 1998; Accepted September 11, 1998)
}

\begin{abstract}
Along the Kamchatka-Kuril-Japan-Izu-Bonin-Mariana subduction zones, the old age of the subducting Pacific Plate and the rapid subduction rate together suggest that earthquakes should occur to the bottom of the transition zone. However, the seismicity cutoff varies in depth between $350 \mathrm{~km}$ and $650 \mathrm{~km}$. Along these subduction zones, the largest deep-focus earthquakes invariably occur near the depth of the local seismicity cutoff regardless of its depth. The events near the seismicity cutoffs also have systematically different focal mechanisms than shallower events. Furthermore, data from $S_{660} P$ arrivals, residual sphere analysis, and tomographic studies all show that the slab dip consistently steepens to a near-vertical orientation at the seismicity cutoff. This change in slab dip indicates a strength loss in the slab. We hypothesize the following causal connection among all these observations: The cold temperatures in the slab kinetically hinder the olivine to spinel phase change and allow the olivine to persist metastably to depths well below its equilibrium pressure. When the phase transition occurs, it nucleates very finegrained spinel which acts as a lubricant, allowing the initiation of earthquake faulting at high confining pressures which further nucleates additional fine-grained spinel. The cold anomaly of the slab severely inhibits the growth of the nucleated spinel crystals. The presence of the fine-grained spinel crystals reduces the strength of the coldest part of the slab by several orders of magnitude, allowing high slab deformation rates. Additionally, the phase change, by increasing the density, provides a negative buoyancy force. Combined, these processes reduce the slab membrane strength and allow the slab to descend at a steeper dip.
\end{abstract}

\section{Introduction}

In some form, deep earthquakes and phase changes, specifically the olivine to spinel phase change, appear interrelated (e.g., Green et al., 1990; Kirby et al., 1996; Bina, 1997). Due to the cold thermal anomaly within a slab, the equilibrium displacements of the 410-km discontinuity to shallower and the $660-\mathrm{km}$ discontinuity to deeper depths apply internal down-dip compression. However, the olivine to spinel phase change in a cold slab may be kinetically hindered (Sung and Burns, 1976; Rubie, 1984), creating a "metastable tongue" of olivine protruding into the transition zone. The delayed transformation of this metastable olivine to spinel may initiate deep earthquakes (Green et al., 1990). In this scenario, deep earthquakes should exist to $660 \mathrm{~km}$ in all rapidly subducting, cold slabs (Kirby et al., 1996). However, in several regions of the northwest Pacific, earthquakes cease at far shallower depths.

This premature cessation in seismicity correlates with several other notable changes in the slab. First, regardless of the depth of the seismicity cutoff, the largest deep-focus earthquakes tend to occur near the depths of the deepest events. Second, the focal mechanisms of the deepest events are systematically different than those at shallower depths. Finally, and perhaps most important, the slab appears to bend to a steeper dip at the seismicity cutoff. The slab dip below the seismicity cutoff is difficult to observe directly. It is in-

Copy right(C) The Society of Geomagnetism and Earth, Planetary and Space Sciences (SGEPSS); The Seismological Society of Japan; The Volcanological Society of Japan; The Geodetic Society of Japan; The Japanese Society for Planetary Sciences. ferred from residual-sphere imaging (Creager and Jordan, 1986), tomographic imaging (Kamiya et al., 1988; van der Hilst et al., 1991, 1998), and the topography of the 660-km seismic discontinuity (Castle and Creager, 1998). In many subduction zones, it appears that the membrane strength of a cold slab prevents it from going to a vertical dip (Chiao, 1991; Creager and Boyd, 1991). Thus, the steepening of the northwest Pacific subduction zones slabs at the deepest earthquakes suggests a decrease in slab strength at that point.

In this study we investigate [1] the spatial distributions of seismicity cutoffs, seismic moment release and moment tensor orientations along the Mariana-Bonin-Izu-Japan-KurilKamchatka subduction system, [2] the geometry of the subducting Pacific slab along the entire arc where the slab is aseismic as well as seismically active, and [3] possible connections between the two involving the olivine-spinel phase change.

\section{Deep Earthquakes}

The old age of the subducting Pacific Plate and the rapid rate of subduction create an extremely cold slab (Kirby et $a l ., 1996)$ with a very large thermal parameter $(\Phi=$ plate age $*$ vertical descent rate) (Karato et al., 1998). Ensuing, earthquakes should occur to the bottom of the transition zone along the entire arc. However, the depth of the deepest earthquakes varies considerably along the arc; ranging from about $350 \mathrm{~km}$ between the Japan and Kuril trenches to $650 \mathrm{~km}$ in the Mariana and Kuril trenches (Fig. 1). Furthermore, the number (Helffrich and Brodholt, 1991) and magnitude of 


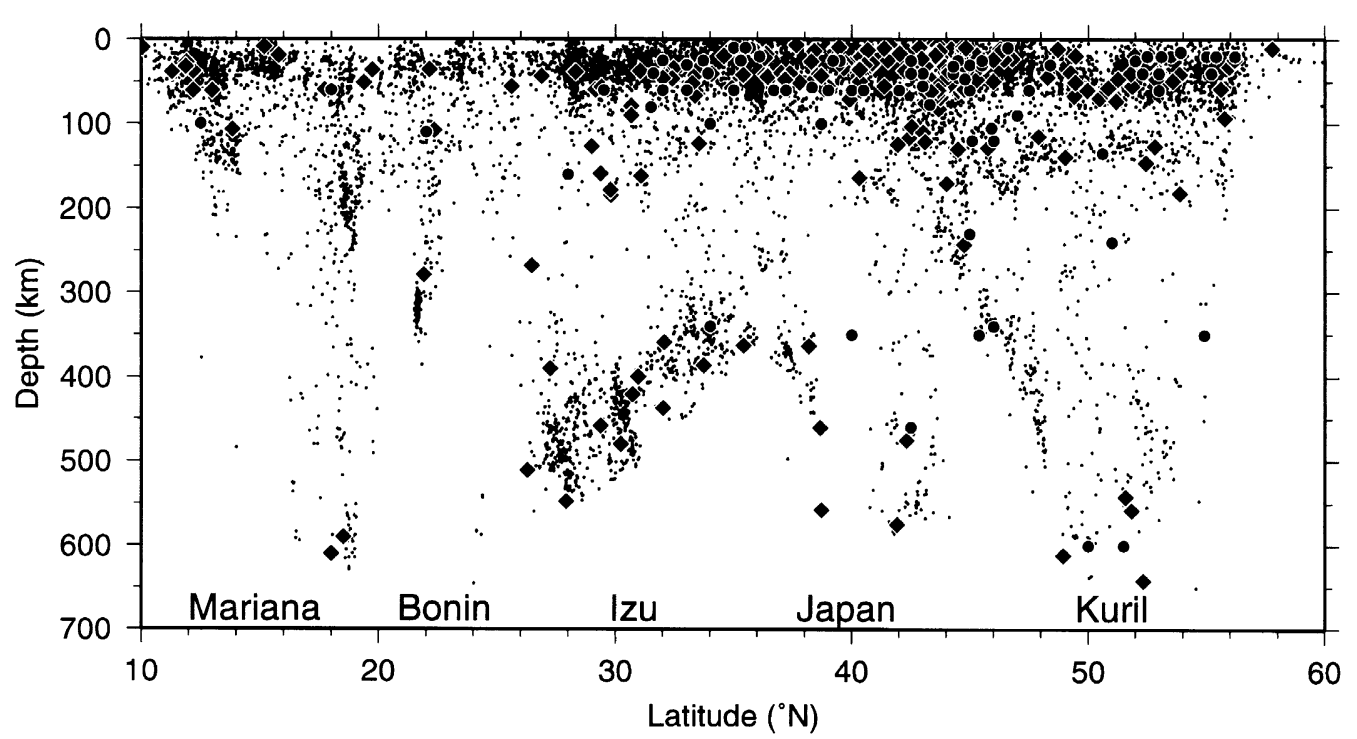

Fig. 1. Points mark Western Pacific earthquakes from 1964 to 1995 (Engdahl et al., 1998). Diamonds (1964-1995, Engdahl et al. (1998)) and bullets (NOAA catalog: 1900-1964, Dunbar et al. (1992)) mark large earthquakes with moments greater than $5.9 m_{b}$. The figure is modeled after Kirby et al. (1996).

earthquakes increases near the seismicity cutoff. In fact, among earthquakes deeper than $200 \mathrm{~km}$, the deepest earthquakes are the largest at each point along the arc and as much as $90 \%$ of the moment release at depths exceeding $200 \mathrm{~km}$ occurs within $75 \mathrm{~km}$ of the seismicity cutoff.

Not only are they larger, the deepest earthquakes have different stress orientations. Figure 2 shows the compressional (P) and extensional ( $\mathrm{T}$ ) axes of earthquake focal mechanisms in the Harvard Centroid Moment Tensor catalog (Dziewonski et al., 1981). Below $100 \mathrm{~km}$, the orientations of the P-axes rotate to down-dip compression (Fig. 2A). Two related explanations of the down-dip compression include: [1] resistance to penetration into the lower mantle (Lundgren and Giardini, 1992) and [2] compressive stresses from buoyancy effects due to thermal perturbations of the $410-\mathrm{km}$ discontinuity (upwards) and 660-km discontinuity (downwards) resulting from equilibrium phase transitions in the cold subducting slab (Bina, 1997). The T-axes of these same earthquakes (Fig. 2C) show extension predominately perpendicular to the plane of the slab, as expected from two dimensional flow models (e.g., Vassiliou et al., 1984; Kincaid and Olson, 1987).

However, the earthquakes within $\sim 50 \mathrm{~km}$ of the seismicity cutoff are systematically different from those above. The strike of the Izu-Bonin trench, at roughly $20^{\circ} \mathrm{W}$ of $\mathrm{N}$, and the convergence between the Pacific and Philippine Plate, at $66^{\circ} \mathrm{W}$ of $\mathrm{N}$ (Seno et al., 1993), create a region of oblique subduction, which causes along-arc shear deformation at depth (Lundgren and Giardini, 1992). The P-axes of earthquakes below $200 \mathrm{~km}$ depth but more than 50-100 km above the seismicity cutoff systematically point down and to the north (Fig. 2B), approximately parallel to expected particle paths owing to the oblique subduction. Within $50 \mathrm{~km}$ (in the north) and $100 \mathrm{~km}$ (in the south) of the seismicity cutoff, the P-axes rotate to pointing down and to the south. The T-axes of these deepest earthquakes (Figs. 2C and 2D, arrows) also change considerably from the seismicity directly shallower. Extension perpendicular to the slab dominates between 200 and roughly $500 \mathrm{~km}$ depth (the long bars between 200 and roughly $500 \mathrm{~km}$ in Fig. 2C). Near the seismic cutoff, however, there exists almost no extension perpendicular to the slab (the short bars in Fig. 2C, arrow), but considerably more extension along the strike of the slab (Fig. 2D, arrow). This change in focal mechanism orientations may result from a weakening in the slab which allows it to respond to the alongarc shear deformation.

That the change in focal mechanism orientation occurs near the bottom of the seismogenic zone regardless of depth, and not at a constant depth in the mantle, implies a peculiarity at the seismic cutoff. The increase of earthquakes at the seismic cutoff and that the largest earthquakes also occur at the cutoff, again regardless of the cutoff depth, reinforces the uniqueness of the cutoff.

\section{Slab Geometry}

Along the entire Kamchatka-Kuril-Japan-Izu-BoninMariana arc, the slab bends to vertical or nearly-vertical at the depth of the deepest seismicity, again, regardless of whether this occurs at $350 \mathrm{~km}$ or $650 \mathrm{~km}$. The evidence for this observation comes from the seismicity itself, analysis of $S_{660} P$ arrival times, residual-sphere modeling, and regional tomographic studies.

\subsection{Mariana trench}

In the Mariana subduction zone, the seismicity defines a vertical slab stretching from just below the surface to the seismicity termination near $660 \mathrm{~km}$ depth (Fig. 3, cross section D-D'). Both residual-sphere modeling (Creager and Jordan, 1986) and tomographic imaging (van der Hilst et al., 1991) show that the slab remains vertical as it descends into the lower mantle. 
A Compressional ( $P$ ) axes

B
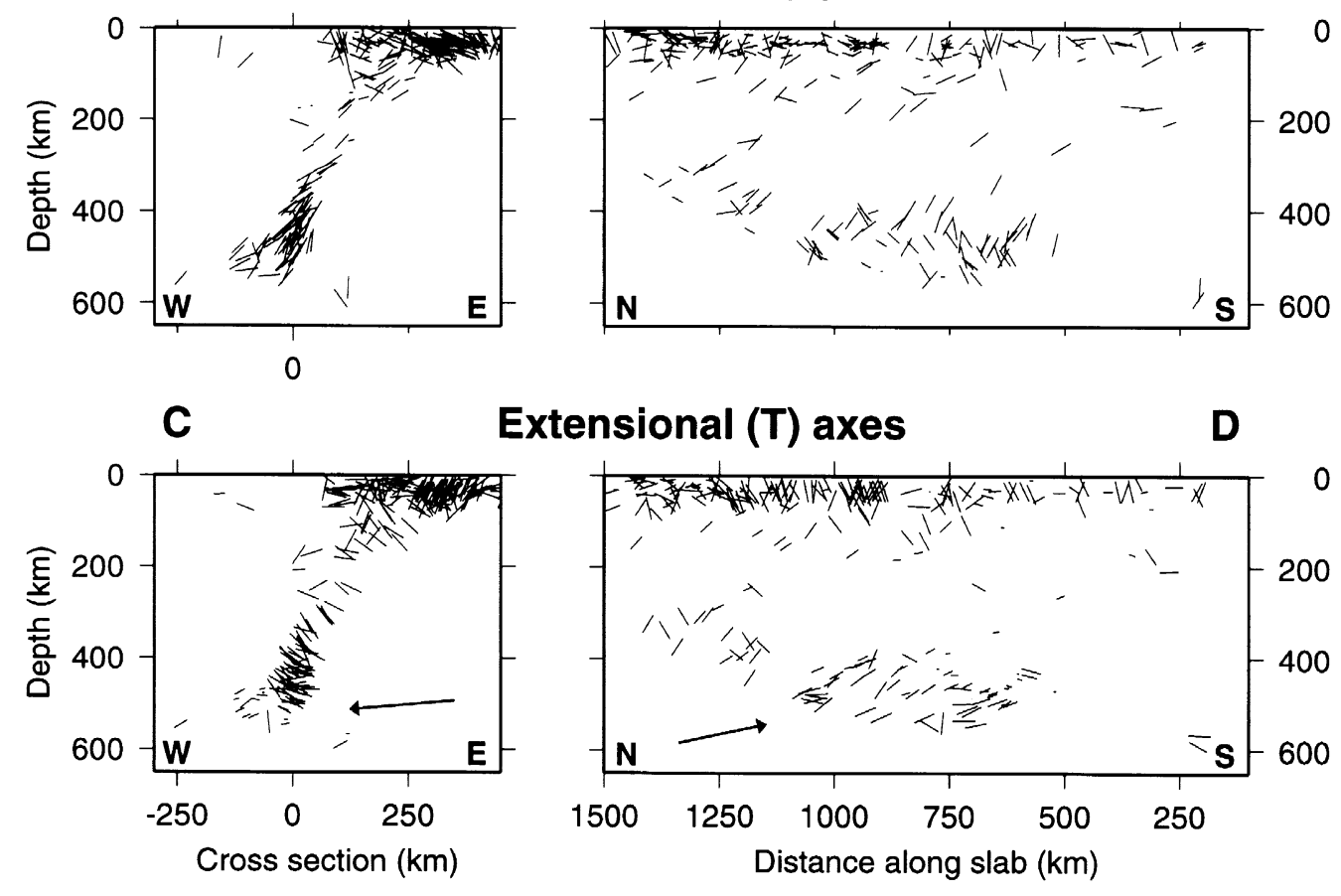

Fig. 2. Izu-Bonin earthquake stress orientations from the Harvard CMT catalog (Dziewonski et al., 1981). P stands for the maximum compression axis; $\mathrm{T}$ stands for the maximum extension axes. The length of the symbol is proportional to the length of the vector in the given plane. The distances along the ordinate are measured from $22^{\circ} \mathrm{N}, 142^{\circ} \mathrm{E}$ perpendicular (A and C) and parallel (B and D) to $340^{\circ}$, the strike of the trench. The arrows highlight the change in orientation of the T-axes at depth. The figure is modeled after Green and Houston (1995).

\subsection{Izu-Bonin trench}

This trench is the most complicated in the system. The membrane strain in this region (the distortion required to fit the Pacific Plate to the seismically defined subducting slab shape) is predicted to be extremely high and requires along-arc extension or tearing (Burbach and Frohlich, 1986; Yamaoka and Fukao, 1986; Creager and Chiao, 1994). Regional residual-sphere analysis studies of the fate of the slab have been inconclusive (Creager, 1984). At the northern end of the trench, near $32^{\circ} \mathrm{N}$, almost all tomographic studies (e.g., Fukao et al., 1992; Widiyantoro, 1997) image a broad, shallowly dipping slab that extends to the west on top of the $660-\mathrm{km}$ discontinuity, probably due to the rapid retreat of the northern Izu-Bonin trench (van der Hilst and Seno, 1993). Similarly, waveform (Brudzinski et al., 1997; Tajima and Grand, 1998) and deep seismicity (Okino et al., 1989; Ohtaki and Kaneshima, 1994) analyses also indicate a slab-like structure exists on top of the $660-\mathrm{km}$ discontinuity extending to the west of the northern Izu-Bonin trench. Conversely, at the southern end of the trench, near $23^{\circ} \mathrm{N}$, tomographic studies (Widiyantoro, 1997) image a steeply dipping slab flowing into the lower mantle.

Furthermore, high resolution maps of topography on the $660-\mathrm{km}$ discontinuity suggest that the slab bends to a vertical dip at the deepest seismicity (Fig. 4) (Castle and Creager, 1998). Assuming the $660-\mathrm{km}$ discontinuity is the endothermic Ringwoodite ( $\gamma$ spinel) to perovskite and magne siowüstite phase change, cold material, such as a subducted slab, will depress the discontinuity. Thus mapping the discontinuity depression maps the slab location at depth.
Near the southern end of the Izu-Bonin trench, near $26^{\circ} \mathrm{N}$, the slab descends steeply to the seismicity cutoff(Fig. 4, cross section Y-Y'). The maximum depression of the $660-\mathrm{km}$ discontinuity lies directly beneath the deepest earthquakes, suggesting that at the seismicity cutoff, the slab falls downward and descends vertically into the lower mantle.

Farther to the north, at $32^{\circ} \mathrm{N}$, historical tectonics associated with rapid trench migration and oblique subduction complicate the picture (van der Hilst and Seno, 1993). The slab dips at roughly $45^{\circ}$ from the surface to the deepest seismicity at $450 \mathrm{~km}$ (cross section X-X', Fig. 4). Unlike the southern region, the discontinuity is depressed for at least several hundred kilometers to the west, consistent with the tomography, waveform, and seismicity observations listed above. However, depression of the $660-\mathrm{km}$ discontinuity again begins directly beneath the deepest earthquakes. We augment the previous studies by suggesting that the slab steepens to a vertical orientation at the deepest seismicity before bending to horizontal near $660 \mathrm{~km}$ depth and extending to the west. Thus both the topography on the $660-\mathrm{km}$ discontinuity and recent tomographic imaging, as discussed in detail in (Castle and Creager, 1998), suggest the Izu-Bonin slab turns to a vertical dip at the seismicity cutoff all along the trench.

\subsection{Japan trench}

Seismicity beneath Japan demarks a slab with an unusually shallow dip of $30^{\circ}$ all the way down to the seismicity cutoff near $600 \mathrm{~km}$ depth (Fig. 3, cross section C-C'). Two pieces of evidence suggest that the slab dip steepens at the seismicity cutoff. Using a method called residual sphere analysis, (Creager and Jordan, 1986) modeled variations in the travel 

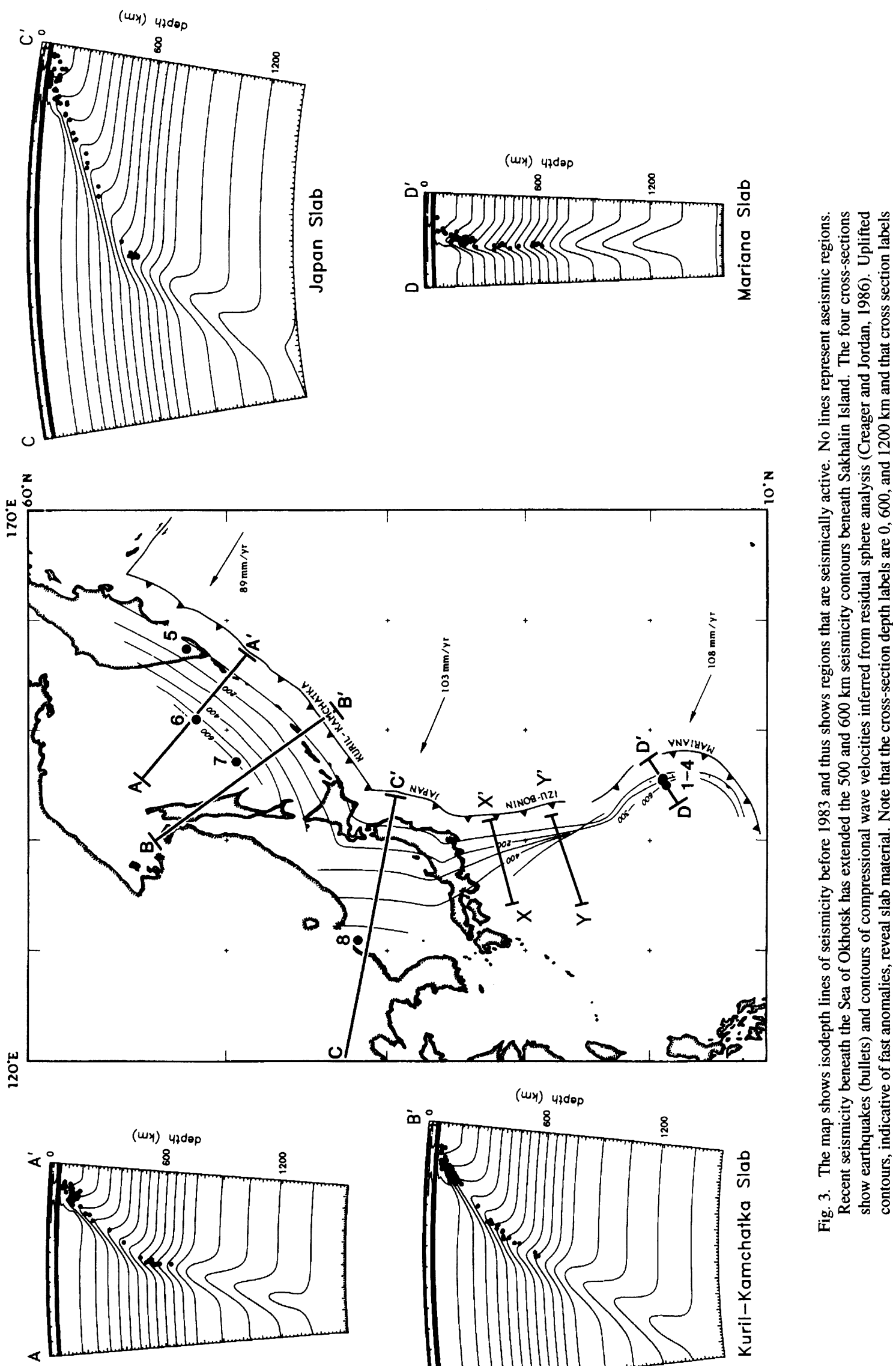

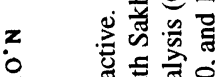

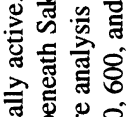

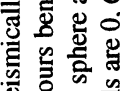

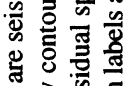

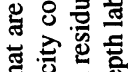

政

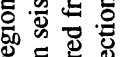

政

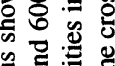

综

政

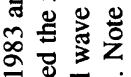

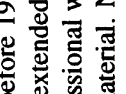

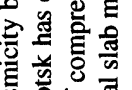

尊

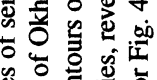

为

क

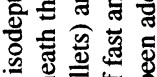

势

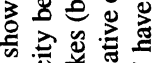

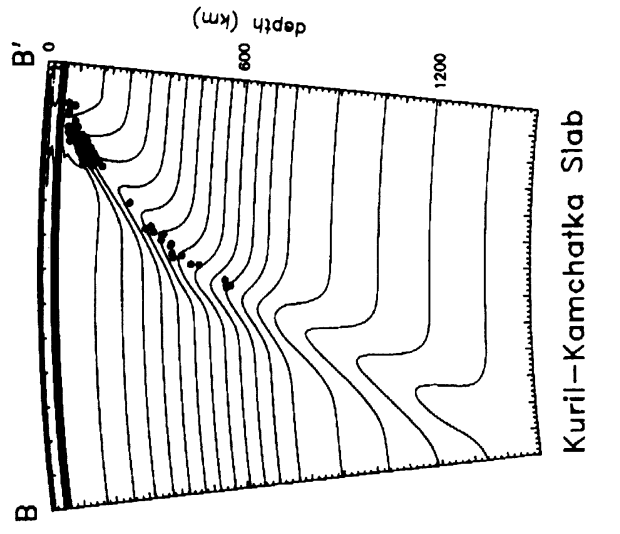

을. 칠

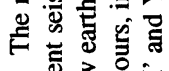

的造言密 


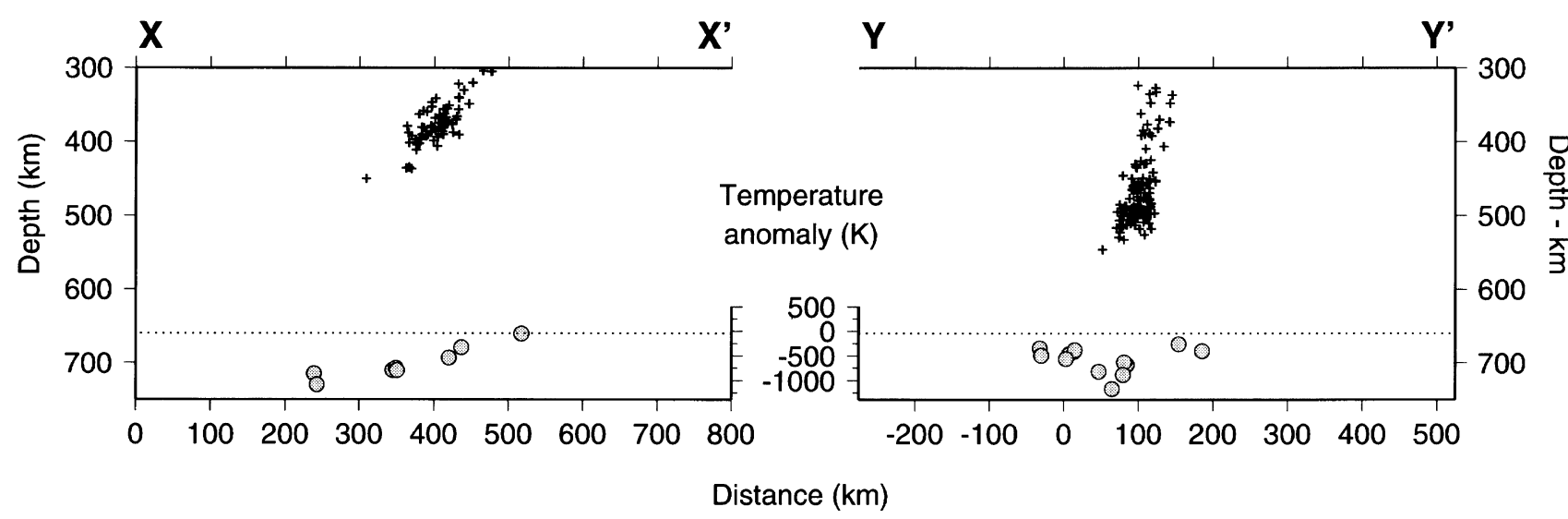

Fig. 4. Izu-Bonin 660-km discontinuity topography (Castle and Creager, 1998). The $x$-axis plots the distance from the point where the slab would intersect the $660-\mathrm{km}$ discontinuity if we extrapolated the seismicity to $660 \mathrm{~km}$ and assumed a straight slab. The cross sections are taken perpendicular to the $200 \mathrm{~km}$ slab contour (iso-line) near $32^{\circ} \mathrm{N}\left(\mathrm{X}-\mathrm{X}^{\prime}\right)$ and $26^{\circ} \mathrm{N}$ (Y-Y') (Fig. 3). Plus signs (+) mark earthquakes and circles (o) show data points within $\pm .5^{\circ}$ of the cross-section. The $660-\mathrm{km}$ discontinuity depth is converted to a temperature using a Clapeyron slope of $-2.8 \mathrm{MPa}^{-1}$ (Ito and Takahashi, 1989). Discontinuity depression indicates the presence of cold slab material.

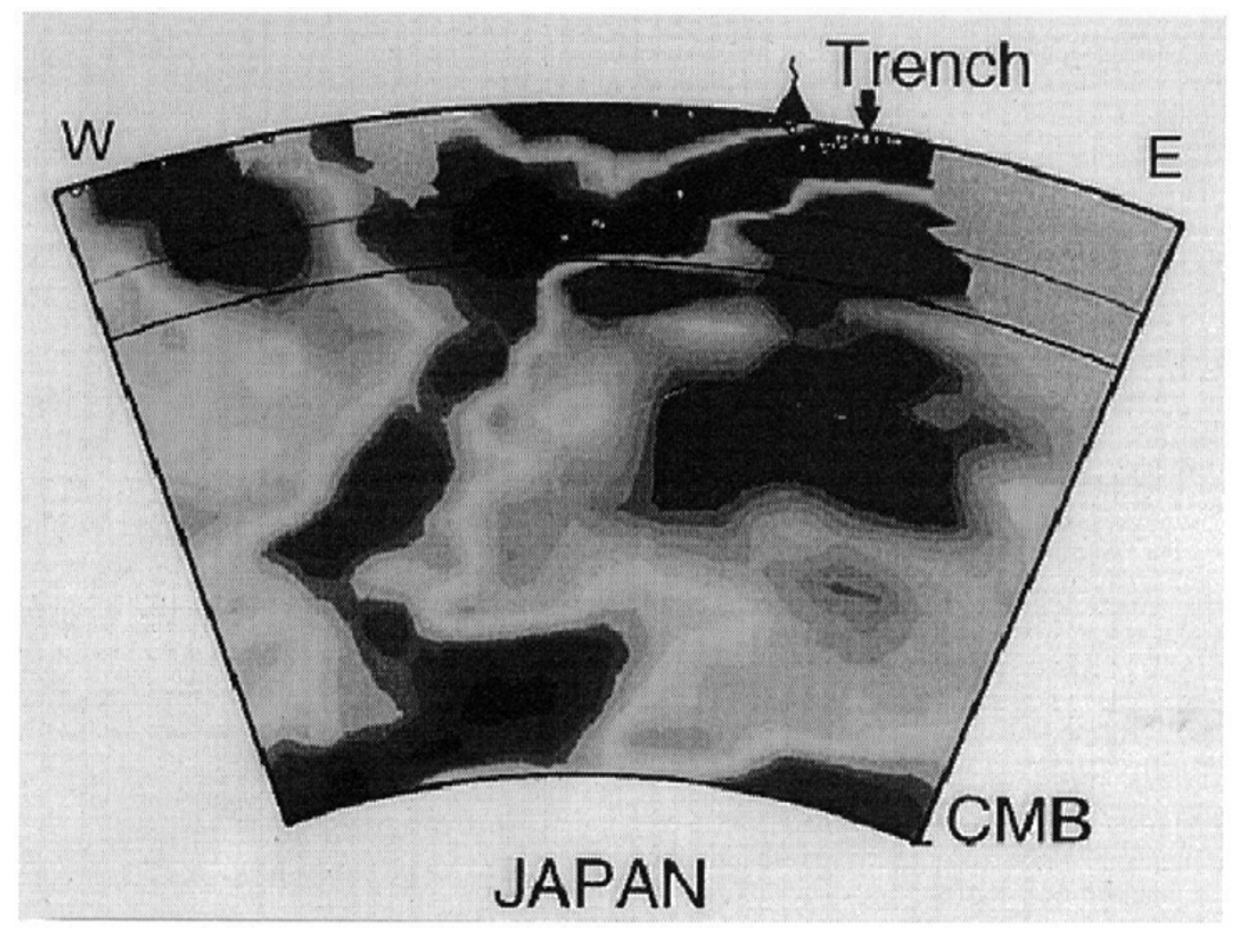

Fig. 5. Compressional-wave velocities below Japan (van der Hilst et al., 1998), close to cross section C-C' in Fig. 3, showing seismicity (dots) and the 410and 660-km discontinuities. The continuous dark region extending from the trench to the core mantle boundary (CMB) shows a fast velocity anomaly that we interpret as cold slab material. All other dark areas represent material with slow velocities.

times of down-going teleseismic $P$ waves from deep earthquakes to map out the location and extent of fast material below the earthquakes. They argue that the slab steepens by at least $30^{\circ}$ near the seismicity cutoff to a dip of at least $60^{\circ}$ depth (Fig. 3, cross section C-C').

The second piece of evidence comes from $P$-wave seismic tomography. Both Kamiya et al. (1988) and van der Hilst et al. (1998) have produced three-dimensional images of the Japan slab which provide further evidence that the Japan slab not only descends into the lower mantle, but bends to a much steeper dip as it does so (Fig. 5). On the other hand, the fast velocities extending west of the deepest earthquakes (Fig. 5) have also been interpreted as cold slab material, suggesting that the slab piles up above $660 \mathrm{~km}$ depth (e.g., Inoue et al., 1990; Fukao et al., 1992).

\subsection{Kuril trench}

This region appears similar to the Japan trench. The slab subducts beneath the surface at roughly $45^{\circ}-55^{\circ}$ and at the 


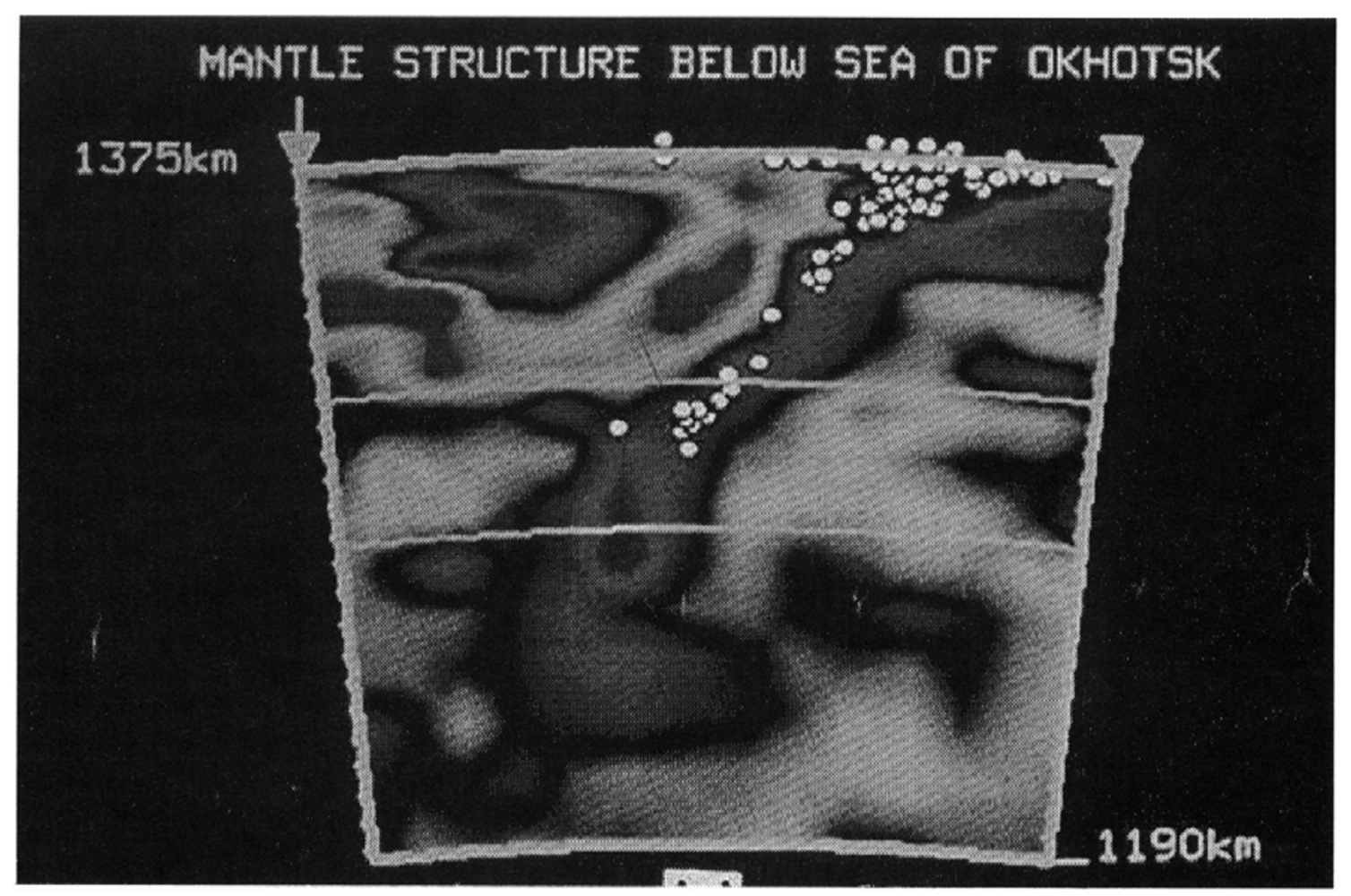

Fig. 6. Compressional-wave velocities below the Sea of Okhotsk (van der Hilst et al., 1991), close to cross section A-A' in Fig. 3. Dots are seismicity and horizontal lines are the 410- and 660-km discontinuities. Two small dark regions, at $250 \mathrm{~km}$ depth on the left margin and $225 \mathrm{~km}$ depth in the middle, show slow anomalies. Other dark regions represent fast material.

deepest seismicity again steepens dramatically. Both the cross sections A-A' and B-B' of the residual sphere analysis (Fig. 3) and the tomographic results of van der Hilst et al. (1991) (Fig. 6) illustrate this steepening well. Additionally, the deepest seismicity along A-A' (Fig. 3) shows this steepening.

\subsection{Slab geometry summary}

While inferences regarding detailed slab geometry derived from the distribution of deep earthquakes are relatively straight forward, the determination of "slab" geometry at depths beyond seismicity cutoffs is less certain. We note that earthquakes tend to terminate when homologous temperatures reach temperatures as low as 0.4 (Creager and Boyd, 1991), while mantle homologous temperatures outside the slab may be as high as 0.9 . As a result, the slab likely remains $500^{\circ}$ to $1000^{\circ}$ colder than normal mantle even below the seismicity cutoff and thus should stay seismically visible. Seismic imaging has lead to conflicting interpretations of the fate of some slabs as they become aseismic, especially in Japan (Creager and Jordan, 1986; Kamiya et al., 1988; Inoue et al., 1990; van der Hilst et al., 1991; Fukao et al., 1992; van der Hilst et al., 1998) as discussed above. However, the evidence discussed previously from seismic imaging using tomography and residual spheres, and from topography of the $660-\mathrm{km}$ discontinuity all suggest that the slab indeed goes vertical at the seismicity cutoff perhaps along the entire subduction system from Kamchatka to the Marianas.

Some areas in the northwest Pacific are less studied and thus more uncertain. The seismicity cuts off very shallowly in the Izu corner (between Izu-Bonin and Japan) and the
Hokkaido corner (between the Kurils and Japan) of the slab; unfortunately these corners are not well imaged. Along the Kamchatka Peninsula, the Pacific Plate and Eurasian Plate converge at a direction normal to the trench; we therefore expect deep earthquakes beneath the Kamchatka Peninsula. Inexplicably, there exists a roughly $500 \mathrm{~km}$ wide aseismic zone parallel to the trench under the peninsula. Continued monitoring will determine whether this region is truly aseismic or simply currently accumulating strain before a large earthquake.

\section{Slab Membrane Strength}

When the trench location is fixed in most two dimensional numerical experiments and physical modeling experiments, dense slabs tend to bend near the surface and subduct nearly vertically into the mantle (e.g., Christensen, 1996; Zhong and Gurnis, 1997). However, slabs are observed to subduct at a variety of angles and several attempts have been made at explaining this discrepancy. Whereas slabs, like a sheet of paper, have little bending strength, the combination of their aspect ratio and high viscosity relative to the warm surrounding mantle gives them considerable membrane strength which plays a critical role in determining the slab geometry (Creager and Boyd, 1991; Creager et al., 1995).

For example, the Japan slab dips at $30^{\circ}$ all the way to $600 \mathrm{~km}$ depth. This is the only slab on Earth with such a shallow dip to great depth. Creager and Chiao (1994) observed that most subduction zones for which the trench has oceanward convex curvature exhibit arch structures characterized by locally shallow slab dips. Examples are Cascadia, 


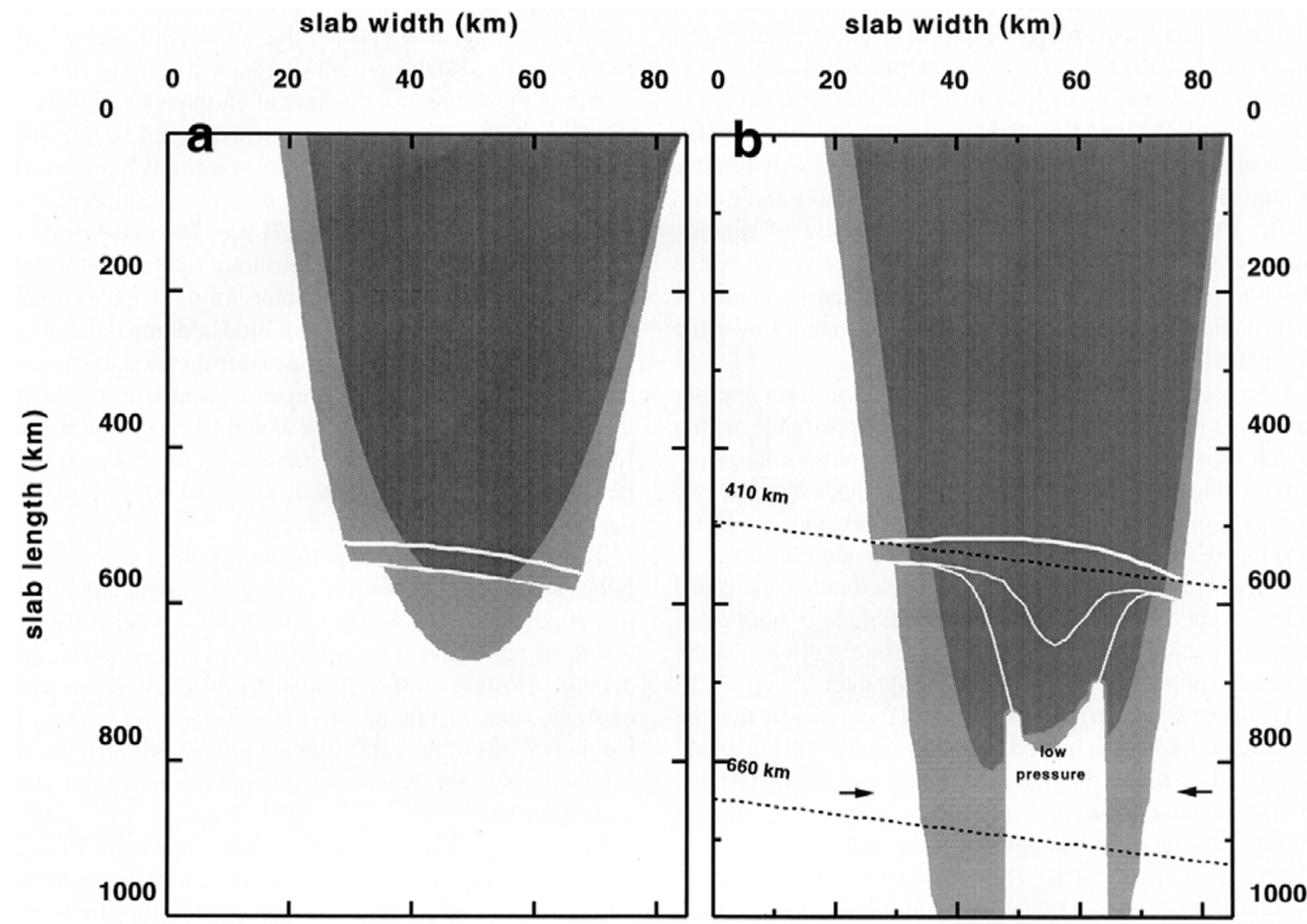

Fig. 7. Slab rheology calculated by Riedel and Karato (1997) for slowly (left; $4 \mathrm{~cm} / \mathrm{yr}$ ) and quickly (right; $10 \mathrm{~cm} / \mathrm{yr}$ ) subducting slabs. Dark gray areas have a Nabarro-Herring creep strength greater than $200 \mathrm{MPa}$; light gray areas, greater than $100 \mathrm{MPa}$; white areas, less than $100 \mathrm{MPa}$. Though not shown in this figure, the creep strength of the cold core of the fast slab drops by 1.5 to several orders of magnitude in the region between the arrows. The axes are slab width versus subducted slab length (not depth) for a $45^{\circ}$ dipping slab. Dashed lines mark 410 and $660 \mathrm{~km}$ depth. Also shown are the depths of the equilibrium phase boundary (upper white line) and depths where $1 \%$ and $99 \%$ of the olivine has converted to spinel. The $1 \%$ and $99 \%$ lines coincide for the "slow" slab.

Alaska, the Hokkaido corner, the Izu corner, and New Britain. In each of these corners there exists extra slab material which can be accommodated by along-arc compression, buckling, or a pronounced arch in the slab geometry, analogous to the pleats in a table cloth hanging off the corner of a table. We postulate that the membrane strength supports each of these arch structures. In the case of the $30^{\circ}$ dip of the Japan slab, the Japan slab is supported by the larger scale membrane strength associated with the Kuril-Bonin arcs which, as a whole, exhibit oceanward convex curvature.

Yamaoka and Fukao (1986) argue that in order for the Pacific Plate to obtain the current shape of this slab requires huge along-arc stretching somewhere between the Marianas and Japan. van der Hilst and Seno (1993) and Castle and Creager (1998) suggest that there exists a vertical tear in the slab near $29^{\circ} \mathrm{N}$ which accommodates most of the extension. To the south, the Mariana slab is then a short, isolated slab segment. This geometry eliminates the effectiveness of membrane strains to control the dip of the Mariana slab and so gravity forces a vertical dip. To the north, the geometry of the long Izu-Bonin to Kurils segment may be largely controlled by membrane strength.

Similarly, if a process, such as earthquakes, reduces the slab strength along a horizontal line, the membrane strength would no longer be able to support a shallow dip and the slab would descend more steeply. Large deep earthquakes could dramatically reduce membrane strength in either a macro- or microscopic fashion. First, the largest earthquakes may tear the slab (Silver and Jordan, 1983; McGuire et al., 1997). Second, on a microscopic level, the phase transition of metastable olivine to spinel transition may allow earthquake faulting at depth, dramatically reducing the constituent grain size, and drastically reducing slab strength until the grains have time to grow (Rubie, 1984; Riedel and Karato, 1997; Karato et al., 1998). In regions of large earthquakes, either one of these, or a combination of the two, could create the zone of weakness necessary to eliminate the membrane strength.

\section{The Olivine to Spinel Phase Change}

We hypothesize that the olivine to spinel phase change is responsible for both the unusual deep earthquakes and the simultaneous change in slab rheology.

In normal mantle, the olivine to spinel phase transformation occurs near a depth of $410 \mathrm{~km}$ and is accompanied by an $8 \%$ density increase (Katsura and Ito, 1989). Because this 
phase change is exothermic, the equilibrium phase change in cold slabs moves to shallower depths which applies a negative (downward) buoyancy force. However, mounting experimental evidence suggests that the low temperatures in the cores of old, rapidly subducting slabs kinetically delay the transformation of olivine to spinel and create a metastable wedge of olivine protruding below 410-km (Sung and Burns, 1976; Rubie, 1984). Depending on the rate of subduction and thermal field in the slab, the wedge could extend down to $660 \mathrm{~km}$, creating an interesting scenario where the metastable olivine transforms directly to magnesiowüstite and perovskite.

Deep earthquakes occur in the depth range from approximately $350 \mathrm{~km}$ to $690 \mathrm{~km}$, the same depth range within which the sharp olivine to modified spinel phase change occurs. Using analogous structures in $\mathrm{Mg}_{2} \mathrm{GeO}_{4}$ and ice, two groups (Green et al., 1990; Kirby et al., 1991) independently developed a theory that deep earthquakes are connected to the olivine to spinel transformation, called either the "anticrack" theory or "transformational faulting." In both theories, as an earthquake ruptures in metastable olivine, small lenses of spinel are created in the fault gouge.

Däßler et al. (1996) recently showed theoretically that the metastable wedge can indeed extend to at least $600 \mathrm{~km}$ depth. Second, they found that the heat released in the metastable olivine to spinel phase change is three times greater than in the equilibrium phase change, resulting in localized heating in the slab of up to $150^{\circ} \mathrm{K}$. They advanced the idea that deep earthquakes occur as a runaway phase transformation, with the latent heat release providing a catalytic effect.

Finally, Riedel and Karato (1997) and Karato et al. (1998) calculated the effect of the olivine to spinel phase change on the slab rheology. In warm slabs, the size of the spinel grains nucleated at olivine grain boundaries is not significantly smaller than the size of the olivine grains. However, in quickly subducting cold slabs, the grain size reduction may be four orders of magnitude. This temperature dependence creates an interesting scenario: immediately following the olivine-spinel phase change, cold slabs are weaker than warmer slabs! Figure 7 shows their modeling results and dramatically displays the weak zone within a quickly subducting slab.

\section{Deep Earthquakes and Slab Rheology}

Throughout the northwest Pacific subduction zones the absolute rate of the Pacific Plate is fast, varying from 80 to $120 \mathrm{~mm} \mathrm{yr}^{-1}$. The subducting lithosphere is very old, ranging from 85 to $130 \mathrm{Ma}$. Under these conditions the slab should be seismically active to $660 \mathrm{~km}$ along its entire length. However, the seismicity ceases at less than $450 \mathrm{~km}$ in four distinct places: under Kamchatka, Hokkaido, Izu, and just north of the Marianas. At these places, we suggest that the slab undergoes catastrophic failure at relatively shallow depths. Large geometric strains in the corners (the "pleats" of the table cloth) may create an intrinsically weak slab. Deformation caused by buoyancy forces integrated over the volume of the subducting plate, including deviatoric stresses, will concentrate where the plate is weakest, inducing the olivine to spinel transformation. Once a critical volume of metastable olivine transforms to spinel, local material continues failing because [1] the heat generated raises temperature by $150^{\circ}$ (Däßler et al., 1996) and [2] the small grain sizes further reduce the local slab strength (Riedel and Karato, 1997).

Along the entire arc, the lack of earthquakes beneath regions of intense seismicity, can be explained in one of the following two ways: [1] the intense seismicity has converted all the olivine to spinel and deep earthquakes require this phase transition to nucleate, or [2] deep earthquakes should be thought of as regions of large strain rates: once the slab dip increases, it has lost the memory of its shape as oceanic lithosphere and can descend with little additional membrane strain. The deep slab is disconnected from the slab above the seismicity, thus there is no longer a geometric reason why the slab must deform. As there would be no geometric need for membrane strains at the slab edges, there would be no geometric deformation at the Kamchatka edge, explaining the lack of deep earthquakes there.

This model explains the following observations in the NW Pacific: intense seismicity near the seismicity cutoffs, a change to a more nearly vertical dip, no seismicity below these regions, and a change in focal mechanism at these depths. However, other than suggesting an accumulation of stress from membrane strength, it does not explain the varying depths of the catastrophic failure along strike in this subduction system. Nor does it attempt to explain slab structures elsewhere.

Synthesizing these results, the subducting Pacific Plate descends from the surface. As the olivine enters the spinel stability field, a metastable olivine wedge develops in the cold slab, providing a positive (upward) buoyancy force which contributes to the shallow slab dip above the seismicity termination. With more subduction, compressive and deviatoric stresses within the slab increase, the olivine begins transforming to spinel, and deep earthquakes occur. Within the cold slab, the olivine to spinel phase transformation nucleates extremely small grains which dramatically reduce the slab strength. The largest earthquakes, where the seismicity ceases, may mark the location where all of the olivine in the metastable wedge has been consumed. At that point, the slab has been thoroughly weakened. The phase change has increased the density of the cold slab, providing an additional downward buoyancy force. The zone of weakness at the seismicity cutoff effectively isolates the deep slab, relieving it of its membrane strength and allowing it to fall vertically downward.

The Ocean Hemisphere Project (OHP), the Japanese initiative to place seismometers throughout the western Pacific oceanic region, will provide data crucial to further test this hypothesis. Receiver studies using data from stations near trenches should create better maps of the $660-\mathrm{km}$ discontinuity topography and thus better reveal the slab location at depth. Data from these stations will also improve regional tomographic imaging by both improving earthquake hypocenter accuracy and increasing the number of raypaths near subducting slabs.

Acknowledgments. An NSF grant supported this research. The authors thank R. van der Hilst, S. Widiyantoro, and T. McSweeney for access to unpublished data and G. Helffrich, S. Karato, and H. Kawakatsu for helpful reviews. 


\section{References}

Bina, C. R., Patterns of deep seismicity reflect buoyancy stresses due to phase transitions, Geophys. Res. Lett., 24, 3301-3304, 1997.

Brudzinski, M. R., W. P. Chen, R. L. Nowack, and B. S. Huang, Variations of $p$ wave speeds in the mantle transition zone beneath the northern Philippine Sea, J. Geophys. Res., 102, 11,815-11,828, 1997.

Burbach, G. V. and C. Frohlich, Intermediate and deep seismicity and lateral structure of subducted lithosphere in the Circum-Pacific region, Rev. Geophys., 24, 833-874, 1986.

Castle, J. C. and K. C. Creager, Topography of the 660-km discontinuity beneath Izu-Bonin: Implications for tectonic history and slab deformation, J. Geophys. Res., 103, 12,511-12,528, 1998.

Chiao, L.-Y., Membrane deformation rate and geometry of subducting slabs, $\mathrm{Ph} . \mathrm{D}$. Thesis, Univ. of Washington, Seattle, 1991.

Christensen, U. R., The influence of trench migration on the slab penetration into the lower mantle, Earth Planet. Sci. Lett., 140, 27-39, 1996.

Creager, K. C., Geometry, velocity structure, and penetration depths of descending slabs in the Western Pacific, Ph.D. Thesis, Univ. of California, San Diego, 1984.

Creager, K. C. and T. M. Boyd, The geometry of Aleutian subduction: Three-dimensional kinematic flow model, J. Geophys. Res., 96, 22932307, 1991.

Creager, K. C. and L.-Y. Chiao, In-plane deformation-rates of circum-Pacific subducting slabs (abstract), in SUBCON An Interdisciplinary Conference on the Subduction Process, vol. 1, pp. 199, Catalina Island, California, 1994.

Creager, K. C. and T. H. Jordan, Slab penetration into the lower mantle beneath the Mariana and other island arcs of the northwest Pacific, $J$. Geophys. Res., 91, 3573-3589, 1986.

Creager, K. C., L. Y. Chiao, J. P. Winchester, and R. Engdahl, Membrane strain rates in the subducting plate beneath south America, Geophys. Res. Lett., 22, 2321-2324, 1995.

Däßler, R., D. A. Yuen, S. I. Karato, and M. R. Riedel, Two-dimensional thermo-kinetic model for the olivine-spinel phase transition in subducting slabs, Phys. Earth Planet. Inter, 94, 217-239, 1996.

Dunbar, P. K., P. A. Lockridge, and L. S. Whiteside, Significant earthquakes worldwide, NOAA earthquake catalog, 1992.

Dziewonski, A. M., T. A. Chou, and J. H. Woodhouse, Determination of earthquake source parameters from waveform data for studies of global and regional seismicity, J. Geophys. Res., 86, 2825-2852, 1981.

Engdahl, E. R., R. D. van der Hilst, and R. P. Buland, Global teleseismic earthquake relocation with improved travel times and procedures for depth determination, Bull. Seismol. Soc. Am., 88, 722-743, 1998.

Fukao, Y., M. Obayashi, H. Inoue, and M. Nenbai, Subducting slabs stagnant in the mantle transition zone, J. Geophys. Res., 97, 4809, 1992.

Green, H. and H. Houston, The mechanism of deep earthquakes, Annu. Rev. Earth Planet. Sci., 23, 169-213, 1995.

Green, H. W., T. E. Young, D. Walker, and C. H. Scholz, Anticrackassociated faulting at very high pressure in natural olivine, Nature, $\mathbf{3 4 8}$, 720-722, 1990.

Helffrich, G. R. and J. Brodholt, Relationship of deep seismicity to the thermal structure of subducted lithosphere, Nature, 353, 252-255, 1991.

Inoue, H., Y. Fukao, K. Tanabe, and Y. Ogata, Whole mantle P-wave travel time tomography, Phys. Earth Planet. Inter., 59, 294-328, 1990.

Ito, E. and E. Takahashi, Postspinel transformations in the system $\mathrm{Mg}_{2} \mathrm{SiO}_{4}$ $\mathrm{Fe}_{2} \mathrm{SiO}_{4}$ and some geophysical implications, J. Geophys. Res., 94, 10,637-10,646, 1989.

Kamiya, S., T. Miyatake, and K. Hirahara, How deep can we see the high velocity anomalies beneath the Japan islands?, Geophys. Res. Lett., 15, 828-831, 1988.

Karato, S. I., M. R. Riedel, and D. A. Yuen, How strong are the subducted slabs?, Earth Planet. Sci. Lett., 1998 (submitted).

Katsura, T. and E. Ito, The system $\mathrm{Mg}_{2} \mathrm{SiO}_{4}-\mathrm{Fe}_{2} \mathrm{SiO}_{4}$ at high pressures and temperatures: Precise determination of stabilities of olivine, modified spinel, and spinel, J. Geophys. Res., 94, 15,663-15,670, 1989.

Kincaid, C. and P. Olson, An experimental study of subduction and slab migration, J. Geophys. Res., 92, 13,832-13,840, 1987.

Kirby, S. H., W. B. Durnam, and L. A. Stern, Mantle phase changes and deep-earthquake faulting in subducting lithosphere, Science, 252, 216225, 1991.

Kirby, S. H., S. Stein, E. A. Okal, and D. C. Rubie, Metastable mantle phase transformations and deep earthquakes in subducting oceanic lithosphere, Rev. Geophys., 34, 261-306, 1996.

Lundgren, P. R. and D. Giardini, Seismicity, shear failure and models of deformation in deep subduction zones, Phys. Earth Planet. Inter, 74, 63-74, 1992.

McGuire, J. J., D. A. Wiens, and P. J. Shore, The March 8, $1994\left(M_{w} 7.6\right)$, deep Tonga earthquake: Rupture outside the seismically active slab, $J$. Geophys. Res., 102, 15,163-15,182, 1997.

Ohtaki, T. and S. Kaneshima, Continuous high velocity aseismic zone beneath the izu-bonin arc, Geophys. Res. Lett., 21, 1-4, 1994.

Okino, K., M. Ando, S. Kaneshima, and K. Hirahara, The horizontally lying slab, Geophys. Res. Lett., 16, 1059-1062, 1989.

Riedel, M. R. and S. I. Karato, Grain-size evolution in subducted oceanic lithosphere associated with the olivine-spinel transformation and its effects on rheology, Earth Planet. Sci. Lett., 148, 27-43, 1997.

Rubie, D. C., The olivine $\rightarrow$ spinel transformation and the rheology of subducting lithosphere, Nature, 308, 505-508, 1984.

Seno, T., S. Stein, and A. E. Gripp, A model for the motion of the Philippine Sea Plate consistent with NUVEL-1 and geological data, J. Geophys. Res., 98, 17,941-17,948, 1993.

Silver, P. G. and T. H. Jordan, Total-moment spectra of fourteen large earthquakes, J. Geophys. Res., 88, 3273-3293, 1983.

Sung, C. M. and R. G. Burns, Kinetics of high-pressure phase transformations: implications to the evolution of the olivine - spinel transition in the downgoing lithosphere and its consequences on the dynamics of the mantle, Tectonophysics, 21, 1-32, 1976.

Tajima, F. and S. Grand, Variation of transition zone high velocity anomalies and depression of $660 \mathrm{~km}$ discontinuity associated with subduction zones from the southern Kuriles to Izu-Bonin and Ryukyu, J. Geophys. Res., 103, 15015-15038, 1998.

van der Hilst, R. D. and T. Seno, Effects of relative plate motion on the deep structure and penetration depth of slabs below the Izu-Bonin and Mariana island arcs, Earth Planet. Sci. Lett., 120, 395-407, 1993.

van der Hilst, R. D., R. Engdahl, W. Spakman, and G. Nolet, Tomographic imaging of subducted lithosphere below northwest Pacific island arcs, Nature, 353, 37-42, 1991.

van der Hilst, R. D., S. Widiyantoro, K. C. Creager, and T. J. McSweeney, Deep subduction and aspherical variations in P-wavespeed at the base of Earth's mantle, in Observational and theoretical constraints on the Core Mantle Boundary Region, edited by M. Gurnis, M. E. Wysession, E. Knittle, and B. A. Buffett, vol. 28, pp. 5-20, American Geophysical Union, Washington, D.C., 1998.

Vassiliou, M. S., B. H. Hager, and A. Raefsky, The distribution of earthquakes with depth and stress in subducting slabs, J. Geodyn., 1, 11-28, 1984.

Widiyantoro, S., Studies of seismic tomography on regional and global scale, Ph.D. Thesis, Aust. Nat. Univ., Canberra, A.C.T., 1997.

Yamaoka, K. and Y. Fukao, Spherical shell tectonics: Effects of sphericity and inextensibility on the geometry of the descending lithosphere, Rev. Geophys., 24, 27-53, 1986.

Zhong, S. and M. Gurnis, Dynamic interaction between tectonic plates, subducting slabs, and the mantle, Earth Interact., 1, 1997.

J. C. Castle (e-mail: castle@geophys.washington.edu) and K. C. Creager (e-mail: kcc@geophys.washington.edu) 
Fig. 3. The map shows isodepth lines of seismicity before 1983 and thus shows regions that are seismically active. No lines represent aseismic regions. Recent seismicity beneath the Sea of Okhotsk has extended the 500 and $600 \mathrm{~km}$ seismicity contours beneath Sakhalin Island. The four cross-sections show earthquakes (bullets) and contours of compressional wave velocities inferred from residual sphere analysis (Creager and Jordan, 1986). Uplifted contours, indicative of fast anomalies, reveal slab material. Note that the cross-section depth labels are 0,600 , and $1200 \mathrm{~km}$ and that cross section labels $\mathrm{X}-\mathrm{X}^{\prime}$ and Y-Y' have been added for Fig. 4. 